\title{
Improving Prediction of Dynamic Zonal Modelling for Atrium Thermal Environment
}

\author{
Yanyu $\mathrm{Lu}^{1,2}$, Yan Xiang ${ }^{1,2}$, Gang Chen ${ }^{3}$, Jing Liu ${ }^{1,2, *}$ \\ ${ }^{1}$ School of Architecture, Harbin Institute of Technology, Harbin, China \\ ${ }^{2}$ Key Laboratory of Cold Region Urban and Rural Human Settlement Environment Science and \\ Technology, Ministry of Industry and Information Technology, Harbin, China \\ ${ }^{3}$ The Architectural Design and Research Institute of Harbin Institute of Technology, Harbin, China
}

\begin{abstract}
The atrium has become a central feature of modern buildings. Predicting the atrium thermal performance, however, still faces lots of challenges. Computational Fluid Dynamics can provide detailed simulation results, but it is not practically applicable to large complex spaces. The conventional zonal models require less computational effort but have a lower accuracy. Thus, this paper aims at improving the dynamic zonal prediction for the case of the atrium thermal environment. Firstly, an airflow network composed of air volumes and flow paths is constructed in the space. Then, a simplified momentum equation is implemented to calculate kinetic energy conservation, transformation and dispassion. By comparing the simulated and measured air temperatures of a five-storey atrium, it is shown the zonal method can obtain a quick and reasonable prediction of atrium thermal performance.
\end{abstract}

\section{Introduction}

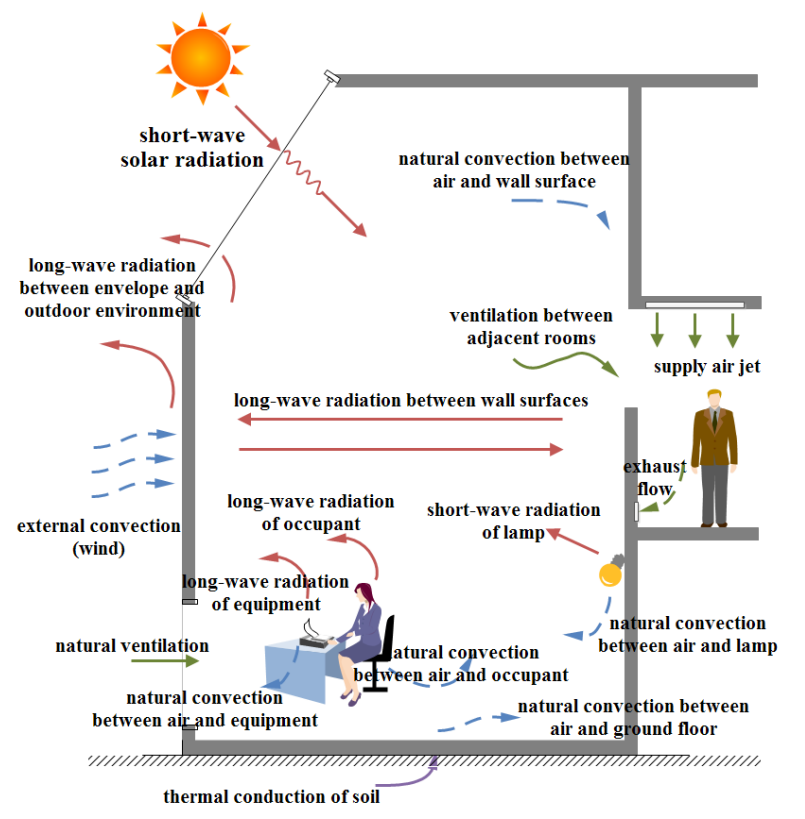

Figure 1: Schematic of atrium thermal environment.
In recent 50 years, the atrium has become more popular in modern society for purpose of aesthetics, natural daylighting and solar heating. It is generally featured with high ceiling, large-volume space and transparent façade or glazed roof. The thermal environment in the atrium is complex and influenced by many interrelated factors, such as ambient environment, adjacent rooms and internal heat sources. A schematic of the physical phenomena in the atrium is presented in Figure 1. The air parameters are unevenly distributed, and there exists thermal stratification (Saxon, 1986; Heiselberg et al., 1998).

For the large-volume space with temperature stratification, the nodal model, considering room air to be homogeneous, is oversimplified. Computational Fluid Dynamics (CFD) modelling can in principle provide detailed and rich results, but it cannot practically be applied to large and complex buildings due to significant problem definition and computational effort (Megri and Haghighat, 2007; Abadie et al., 2012). On this occasion, the zonal model, as a good compromise between efficiency and accuracy, has been put forward. In many cases, the power law model is employed to determine the mass flow rate between the adjacent zones (Voeltzel et al., 2001; Beiza et al., 2014; Fang et al., 2017). But there exist some limitations and deficiencies. For example, the simulation results are closely related to zoning method, because it implicitly presumes that viscous dissipation merely occurs at the cell boundaries (Axley., 2001). Then, a velocity propagating zonal model was developed to improve the accuracy of the zonal method (Norrefeldt et al., 2012). The application of this model, however, has not been fully matured, especially for the atrium with complicated boundaries and obvious thermal stratification. 


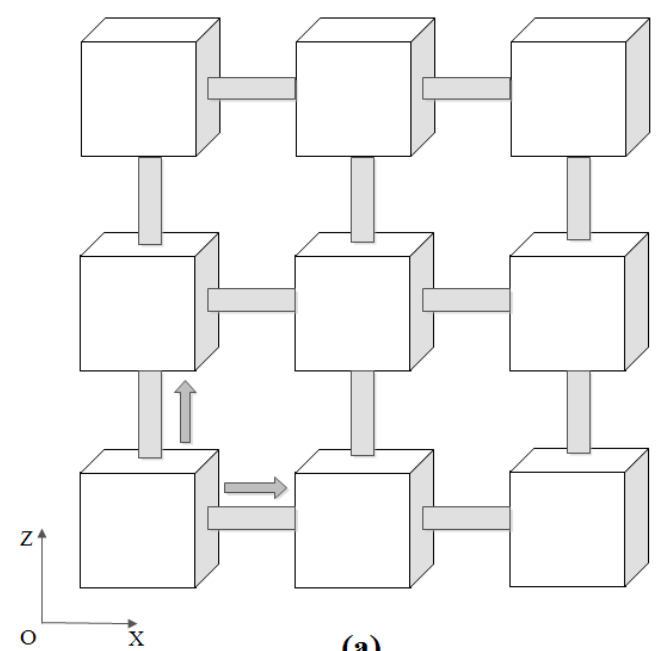

(a)

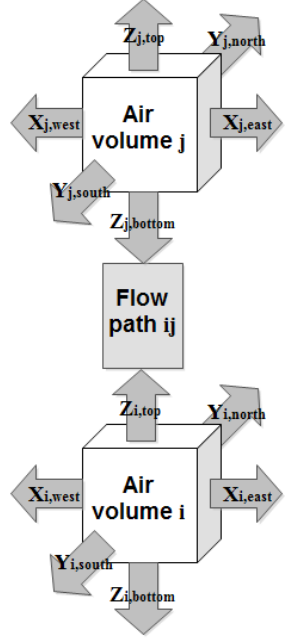

(b)

Figure 2: Zonal model in x-z direction: (a) fluid network, (b) air volume-flow path connection.

\section{Description of the zonal model}

\section{Governing equations}

Zonal models decompose a room into a limited number of perfectly mixed air zones, typically 10-100 (Norrefeldt et al., 2012). These zones are inter-connected between which transfer air flow and heat flux. As shown in Figure 2, a fluid network is constructed within the room: air volumes and flow paths. In this way, air information, such as velocity and temperature, can spread all over the space.

Inside each air volume, e.g. $i$, the air properties (temperature, pressure and density) are calculated by solving mass and energy balance equations as follows:

$$
\begin{gathered}
\rho_{i}=\frac{P_{i}}{R T_{i}} \\
\sum_{j} \dot{m}_{j \rightarrow i}+\sum_{\text {sources }} \dot{m}_{\text {source } \rightarrow i}=0 \\
\rho_{i} C_{\mathrm{p}} V_{i} \frac{d T_{i}}{d \tau}=\sum_{j \neq i} \dot{m}_{j \rightarrow i} C_{\mathrm{p}}\left(T_{j}-T_{i}\right) \\
+\sum_{\text {walls }} h_{\text {wall }, i} A_{\text {wall }, i}\left(T_{\text {wall }, i}-T_{i}\right) \\
+\sum_{\text {sources }} \dot{Q}_{\text {source }, i}
\end{gathered}
$$

where $T$ is temperature, $\mathrm{K} ; P$ is air pressure, $\mathrm{Pa} ; \rho$ is air density, $\mathrm{kg} / \mathrm{m}^{3} ; \dot{m}$ is mass flow rate, $\mathrm{kg} / \mathrm{s} ; \dot{Q}$ is heat source, $\mathrm{W} ; h$ is convective heat transfer coefficient, $\mathrm{W} /\left(\mathrm{m}^{2} \cdot \mathrm{K}\right) ; V$ is zonal volume, $\mathrm{m}^{3} ; A$ is zonal interface area, $\mathrm{m}^{2} ; \tau$ is time, $\mathrm{s} ; C_{\mathrm{p}}$ is specific heat, $\mathrm{J} /(\mathrm{kg} \cdot \mathrm{K}) ; R$ is gas constant for air, $\mathrm{J} /(\mathrm{kg} \cdot \mathrm{K})$. The subscripts refer to specific zones, surfaces or sources. In addition, entering airflow is assumed positive while leaving airflow is negative.

In the power law model, the mass flow rate between the adjacent zones $\dot{m}_{j \rightarrow i}$ is computed merely based on the pressure difference $\left(P_{j}-P_{i}\right)$, as given in Eq. (4). $C_{\mathrm{d}}$ is discharge coefficient, $n$ is air flow exponent.

$$
\dot{m}_{j \rightarrow i}=\rho A C_{\mathrm{d}}\left(P_{j}-P_{i}\right)^{n}
$$

In this paper, to obtain air velocity $w_{i j}$ and flow rate $\dot{m}_{j \rightarrow i}$, a reduced form of Navier-Stokes equation, Eq. (5), is established on the flow path. Taking the air flow in $z$-direction as an example as showed in Eq. (6), the momentum equation is balanced by pressure force $\left(F_{\mathrm{P}}\right)$, momentum force $\left(F_{\mathrm{M}}\right)$, gravitational force $\left(F_{\mathrm{G}}\right)$, and viscous force $\left(F_{\mathrm{V}}\right)$. The introduction of the length of an airflow path, $\Delta z_{i j}$, enables the momentum loss to be governed by design parameters instead of grid spacing.

To avoid the dissipation of airflow velocity within the zones as in the conventional power law model, a characteristic velocity vector, $w$, is assigned to each air volume and used in Eq. (6). Considering airflow can propagate into downstream zones, characteristic velocities are defined as in Figure 3. Besides, an apparent viscosity, $\mu_{a}$, is used as a tuning parameter in the model to take turbulent losses into account. In this paper, $\mu_{a}$ was set as $0.001 \mathrm{~Pa} \cdot \mathrm{s}$ to produce simulation results that 
match with the measurement data.

$$
\begin{gathered}
A \cdot \Delta z_{i j} \cdot \rho \cdot \frac{d w_{i j}}{d \tau}=F_{\mathrm{P}}+F_{\mathrm{M}}+F_{\mathrm{G}}+F_{\mathrm{V}} \\
F_{\mathrm{P}}=A \cdot\left(P_{i}-P_{j}\right) \\
F_{\mathrm{M}}=\rho \cdot A \cdot\left(w_{i}^{2}-w_{j}^{2}\right) \\
F_{\mathrm{G}}=-\rho \cdot g \cdot A \cdot \Delta z_{i j} \\
F_{\mathrm{v}}=\frac{\left(F_{\mathrm{cell}, i}+F_{\mathrm{cell}, j}\right)}{2} \\
F_{\text {cell }}=\mu_{a} \cdot\left\{\left[\left(\frac{\Delta w}{\Delta x}\right)_{\mathrm{e}}-\left(\frac{\Delta w}{\Delta x}\right)_{\mathrm{w}}\right] \cdot A_{\mathrm{YZ}}\right. \\
\left.+\left[\left(\frac{\Delta w}{\Delta y}\right)_{\mathrm{n}}-\left(\frac{\Delta w}{\Delta y}\right)_{\mathrm{s}}\right] \cdot A_{\mathrm{XZ}}\right\}
\end{gathered}
$$

\section{Boundary conditions}

Generally, the large atrium space is partly occupied and the usage zone ratio is small. A uniform heat source over the whole floor area is hypothesized, that is, the floor is modelled as a no-slip wall boundary with a fixed heat flux. In addition, a recommended convection to radiation ratio is adopted, for example 2:1 for personnel (Pan et al., 2018).

On one hand, solar radiation directly impacts the skylight. The glazed system can be set as the heat flux boundary condition. On the other hand, some parts of wall surfaces absorb the transmitted sunlight and probably form an inhomogeneous temperature distribution (Heiselberg et al., 1998). In this study, the experimentally-determined wall surface temperatures were applied as the boundary conditions to validate the zonal model.

A correlation for the natural convective heat transfer coefficient, $h$, is available in Eq. (7), which relies on the wall position and the temperature difference between wall surface and air, $\left(T_{\mathrm{s}}-T_{\mathrm{f}}\right)$ (Yoshiroku et al., 1999).

$$
h=c\left(T_{\mathrm{s}}-T_{\mathrm{f}}\right)^{0.25}
$$

where $c$ is $2.67 \mathrm{~W} /\left(\mathrm{m}^{2} \cdot \mathrm{K}^{1.25}\right)$ for the ceiling of a cold room or the floor of a warm room, $0.64-0.37 \mathrm{~W} /\left(\mathrm{m}^{2} \cdot \mathrm{K}^{1.25}\right)$ for the opposite case, and $1.98 \mathrm{~W} /\left(\mathrm{m}^{2} \cdot \mathrm{K}^{1.25}\right)$ for the vertical wall surface.

\section{Implementation of the model and resolution procedure}

This model consists of nonlinear equations, which results in an iterative resolution procedure, as presented in Figure 4. The program of the zonal method was newly developed in the object-oriented $\mathrm{C}++$ language. The main input to the model consists of geometric characteristics of the enclosure, boundary conditions and internal heat sources, etc. The output includes temperature and airflow patterns.

Because the number of zones in the zonal method is much less than that of CFD, we use the simultaneous solution for the momentum and mass equations. Firstly, the air velocities in $x$-, $y$ - and $z$-direction and pressures, i.e. $\{\boldsymbol{U} \boldsymbol{V} \boldsymbol{W} \boldsymbol{P}\}$, are considered as macroscopic system variables. Then, Eq. (1), (5) and (6) of the mathematical model is described with a global system of linear equations, as given in Eq. (8).

$$
\left[\begin{array}{cccc}
\boldsymbol{V}_{\mathbf{X}} & 0 & 0 & F_{\mathrm{X}} \\
0 & \boldsymbol{V}_{\mathrm{Y}} & 0 & \boldsymbol{F}_{\mathrm{Y}} \\
0 & 0 & \boldsymbol{V}_{\mathrm{Z}} & \boldsymbol{F}_{\mathrm{Z}} \\
\boldsymbol{M}_{\mathrm{X}} & \boldsymbol{M}_{\mathrm{Y}} & \boldsymbol{M}_{\mathrm{Z}} & 0
\end{array}\right]=\left[\begin{array}{c}
\boldsymbol{U} \\
\boldsymbol{V} \\
\boldsymbol{W} \\
\boldsymbol{P}
\end{array}\right]=\left[\begin{array}{c}
\boldsymbol{S}_{\mathrm{X}} \\
\boldsymbol{S}_{\mathrm{Y}} \\
\boldsymbol{S}_{\mathrm{Z}} \\
0
\end{array}\right]
$$

where $\boldsymbol{V}$ is the coefficient matrix of air velocity; $\boldsymbol{F}$ is the coefficient matrix of pressure; $\boldsymbol{M}$ is the matrix associated with mass conversation; $\boldsymbol{S}$ stands for the constant matrix.

This coefficient matrix cannot satisfy the Scarborough criterion. To solve this ill-conditioned matrix, the energy functional method is utilized. For a system of linear equations with a singular coefficient matrix, $\boldsymbol{A} \boldsymbol{X}=\boldsymbol{Y}$, the problem can be converted to Eq. (9) (Anthony et al., 1990). A penalty factor, $\alpha$, of $10^{-15}$ was used.

$$
\min \|\boldsymbol{A} \boldsymbol{X}-\boldsymbol{Y}\|^{2}+\alpha\|\boldsymbol{X}\|^{2}
$$

Furthermore, some numerical techniques are employed to enhance the robustness and efficiency of this algorithm: additional source term for the flux boundary condition; linear relaxation used to stabilize the numerical simulation, etc (Patankar, 1980). The initial air temperature was set as $23{ }^{\circ} \mathrm{C}$, the flow velocity was 0 $\mathrm{m} / \mathrm{s}$, and the corresponding air pressure was standard atmospheric pressure, $101325 \mathrm{~Pa}$. The convergence criteria of temperature and pressure were $10^{-6}$, and others were set as $10^{-4}$.

\section{Case study}

\section{Overview of the target atrium}

The atrium building is a typical office building, which is 


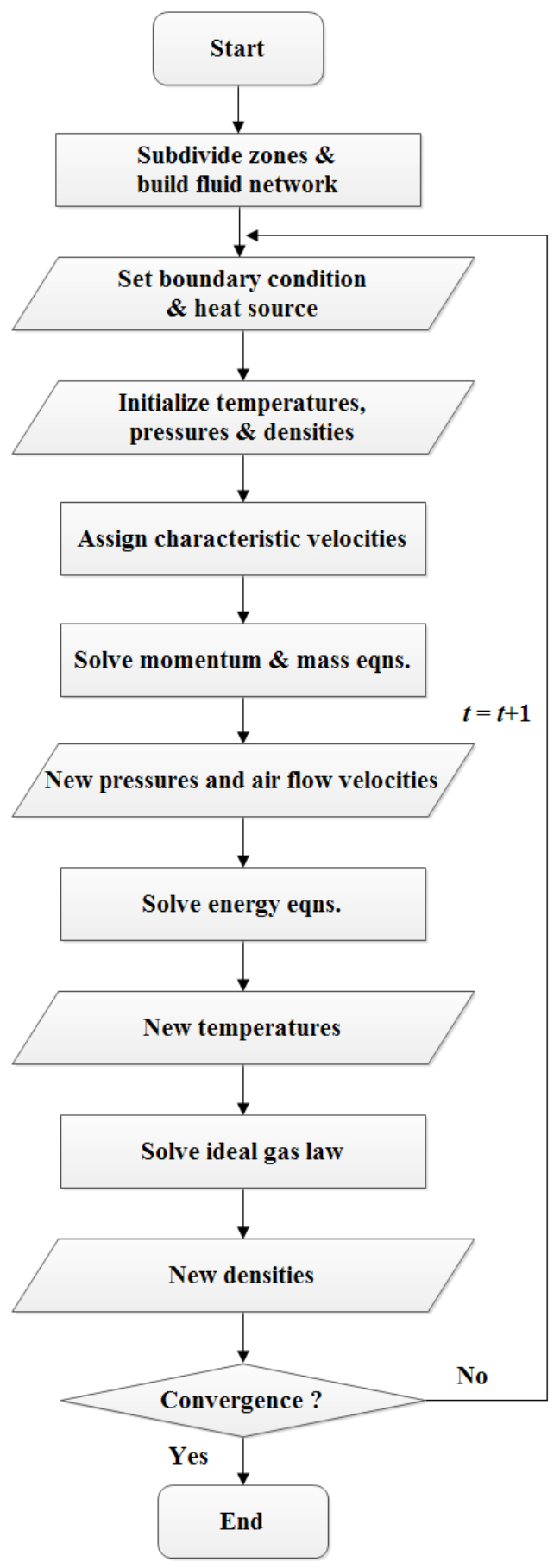

Figure 4: Flowchart of the iterative resolution procedure of the zonal model.

located in Harbin, a capital city in China $\left(45^{\circ} 41^{\prime} \mathrm{N}\right.$ $\left.126^{\circ} 37^{\prime} \mathrm{E}\right)$. This five-storey atrium covers an area of 275 $\mathrm{m}^{2}$ and measures $22.85 \mathrm{~m}$. As shown in Figure 5, the rectangular atrium space is the main core of the building and surrounded by offices on three sides. It is topped with a pyramidal skylight, and this glazing system has a solar transmittance of $25 \%$ and a $U$-value of $2 \mathrm{~W} / \mathrm{m}^{2} \cdot \mathrm{K}$. The atrium cannot be mechanically or naturally ventilated. It houses two elevators, which were rarely used during the measurement.

\section{Field measurement scheme}

To study the atrium thermal stratification, the field measurements were carried out in the typical summer days of Harbin from $16^{\text {th }}$ to $26^{\text {th }}$ June 2018. The tested parameters included weather condition, air temperature, wall and ground surface temperature. As shown in Figure 6 , in order to fully reflect the air temperature distribution, a total of 45 thermocouples with an uncertainty of $0.4 \%$ were almost evenly distributed inside the atrium apace. Before the measurement, the temperature sensors were calibrated through an oil bath test. To protect from direct solar radiation during the test, especially at the daytime, a simple radiation shielding hood was made for each thermocouple using tinfoil. The surface temperatures in all orientations at different heights were measured via button temperature loggers with an accuracy of $0.0625^{\circ} \mathrm{C}$. Also, the floor temperatures were tested in a quincuncial arrangement. A HOBO automatic weather station was arranged at the rooftop to record weather data, such as global solar radiation and outdoor air temperature. These parameters were measured intermittently at 10-minute intervals; then the average values were calculated for each hour.

\section{Comparison of the simulated and measured results}

As demonstrated in Figure 7, the pyramid skylight was simplified as a flat roof. The side walls were presumptively planes. Considering accuracy and efficiency at the same time, the atrium was subdivided into $5 \times 5 \times 5=125$ zones. The walls were discretized into 5 layers in order to account for thermally stratified wall surfaces. The per capita occupation area index was 20 $\mathrm{m}^{2} /$ person during office hour, and the heat flux from one person was $61 \mathrm{~W}$ at $26{ }^{\circ} \mathrm{C}(\mathrm{Lu}, 2007)$. Other calculation conditions were set as measurement data. 22 June 2018 was chosen as the case scenario in this paper. As shown in Figure 8, the outdoor temperature ranged between $20.1{ }^{\circ} \mathrm{C}$ and $34.0{ }^{\circ} \mathrm{C}$, and the maximum global solar radiation was $733.7 \mathrm{~W} / \mathrm{m}^{2}$.

As demonstrated in Figure 9, the predicted hourly air temperatures changed almost consistently with the measurement results. The maximum air temperature 
difference varies between $-1.2{ }^{\circ} \mathrm{C}$ and $1.5{ }^{\circ} \mathrm{C}$, and the root-mean-squared error (RMSE) is between $0.2{ }^{\circ} \mathrm{C}$ and $0.8{ }^{\circ} \mathrm{C}$. Figure 10 gives detailed comparisons of the simulated and measured air temperature profiles at some typical moments. At nighttime, the air temperatures as predicted and measured increase linearly with atrium height, but overall the air tends to be well-mixed. In midday, the simulated and measured air temperatures on the $1^{\text {st }}$ floor are around $27^{\circ} \mathrm{C}$, slightly beyond the limit of comfort zone. The air temperature quickly adds up below the skylight, and it reaches above $34{ }^{\circ} \mathrm{C}$ on the $5^{\text {th }}$ floor. Furthermore, a pronounced thermal stratification is observed. A dimensionless non-uniformity coefficient of temperature, $\varphi$, is defined as in Eq. (10):

$$
\varphi=\frac{\left|T_{\mathrm{t}}-T_{\mathrm{b}}\right|}{T_{\mathrm{av}}}
$$

where $T_{\mathrm{av}}$ is the average zone temperature; $T_{\mathrm{t}}$ and $T_{\mathrm{b}}$ are the temperatures at the top and bottom of the zone, respectively. A higher value indicates a greater temperature discrepancy. The peak $\varphi$ value in both simulation and measurement was 0.2 at 12:00.

But particularly, when the skylight began to absorb solar radiation and the wall surfaces were heated up in the morning, the air temperatures above the $3^{\text {rd }}$ floor are somewhat overestimated. While sunlight faded in the afternoon, the case is opposite. These discrepancies may be due to the two facts: On one hand, the building layout and geometry property were simplified, and the tiny air infiltration was neglected in the simulation; On the other hand, the zonal model is more sensitive to a change in boundary condition than the measurements show. But from the comparisons given above, it is evident that the zonal model is generally able to forecast the dynamic thermal environment in the atrium.

\section{Comparison of zonal model and CFD method}

To further evaluate the zonal model in accuracy and efficiency, a comparative trial study was conducted using CFD calculation. The case at 12:00 was selected, which showed a noticeable thermal stratification. The CFD model was created with commercial solver FLUENT ${ }^{\circledR}$. A grid of 1.23 million hexahedral cells proved to be sufficient, as shown in Figure 11. The grid density was increased near where apparent velocity and temperature gradients were expected, such as solid walls. The minimum cell size near each wall was chosen, leading to $\mathrm{y}+$ value $\leq 10$. As the previous studies indicated (Pan et al., 2018; Hussain and Oosthuizen, 2012), the SST- $k-\omega$ turbulence model was employed for airflow simulation in the large-volume building. The Boussinesq approximation was used to model the buoyance force. The boundary conditions of the atrium and the thermal properties of its materials were based on the measurement as in the zonal modelling. The discrete equations were solved using the SIMPLE pressure-velocity coupling algorithm. The second-order upwind scheme was used to discretize the momentum, turbulent kinetic energy, dissipation rate and energy conservation equations. In the unsteady-state calculation, a time step of $1 \mathrm{~s}$ was determined. The convergence criterion of energy was $10^{-6}$, and the other convergence criteria were $10^{-3}$.

Figure 12 presents a comparison of air temperature profiles obtained by the on-site measurement, the zonal method and CFD calculation. Above the $3^{\text {rd }}$ floor with strong solar radiation, the simulated air temperatures of these two models show a good agreement, and the CFD results well match the measurement data. On the $1^{\text {st }}$ floor with small internal heat source, there is also little difference between them. But on the middle floors, both of the predicted air temperatures deviate from the measurement results. Possibly because the effects of thermal buoyance and solar radiation on air flow are not thoroughly considered in the existing simulations. But in general, the results from the zonal model are comparable to those of the CFD simulation.

Apart from accuracy, computing time to reach convergence is also important to assess airflow models. A dimensionless computational time ratio, $N$, is defined as in Eq. (11):

$$
N=\frac{t_{\text {physical }}}{t_{\text {elapsed }}}
$$

where $t_{\text {physical }}$ is the physical time of air flow motion, s; $t_{\text {elapsed }}$ is the elapsed computing time of simulation, $\mathrm{s}$. On an Intel ${ }^{\circledR}$ Core $^{\mathrm{TM}}$ i7-7700 CPU @ 3.60 GHz, 16.0 GB RAM desktop computer, the $N$-values of the zonal model and CFD are 8.1 and 1.1, respectively. Due to the complicated boundary conditions and large-volume space, the simulation for atrium thermal environment requires 
significant computational efforts. The CFD computing time is almost the same as the physical time, and the zonal method is clearly faster. Through the cross-validation with CFD, it is proved that the zonal model is able to obtain a quick and accurate prediction of the atrium thermal environment in general.

\section{Conclusion}

In summertime, overheating could be a serious problem in the upper part of a medium atrium. The air temperature reached above $34{ }^{\circ} \mathrm{C}$ on the $5^{\text {th }}$ floor at 12:00. Besides, there was a pronounced thermal stratification. The non-uniformity coefficient of air temperature $\varphi$ was 0.2 in midday. In this paper, a three-dimensional, physics-based zonal model was developed to relate the temperature distribution to the spatial mass flow rate. To improve the accuracy of simulation results, a simplified momentum equation was established, introducing the length of the flow path, the characteristic velocity and the apparent viscosity. Then, a novel $\mathrm{C}++$ resolution procedure was elaborated. By comparing the simulated and measured data, it is shown that the zonal model is able to not only reflect the general trend of thermal stratification but also obtain the reasonable value of air temperature. The maximum air temperature deviation varies between $-1.2^{\circ} \mathrm{C}$ and $1.5^{\circ} \mathrm{C}$, and the root-mean-squared error (RMSE) is between $0.2{ }^{\circ} \mathrm{C}$ and $0.8^{\circ} \mathrm{C}$. Furthermore, the results obtained by the zonal method are comparable to those from CFD simulation, and this model is 8 times faster than the latter. Yet, there is still some uncertainty about the zonal model. One important future enhancement to better the atrium environment simulation is to further consider the effect of thermal buoyancy and solar radiation on air flow.

\section{Acknowledgment}

The authors are grateful that this research was supported by "the 13th Five-Year" National Key R\&D Program of China (Grant No. 2017YFC0702200).

\section{References}

Abadie, M. O., Camargo, M. M. D., Mendonça, K. C., et al. (2012). Improving the prediction of zonal modeling for forced convection airflows in rooms. Building \& Environment 48, 173-182.
Axley, J. W. (2001). Surface-drag flow relations for zonal modeling. Building \& Environment 36, 843850.

Beiza, M., Ramos, J. C., Rivas, A., et al. (2014). Zonal thermal model of the ventilation of underground transformer substations: Development and parametric study. Applied Thermal Engineering 62, 215-228.

Fang, H., Zhao, D., Tan, G., et al. (2017). Study of underfloor air distribution using zonal model-based simulation and experimental measurements. Energy \& Buildings 152, 96-107.

Fiacco, A. V., \& McCormick, G. P. (1990). Nonlinear Programming Sequential Unconstrained Minimization Techniques. Society for Industrial and Applied Mathematics. Philadelphia (the United States).

Heiselberg, P., Murakami, S., Roulet, C. A. (1998). Ventilation of Large Spaces in Buildings. IEA Annex 26 Report. Department of Building Technology and Structural Engineering, Aalborg University. Aalborg (Denmark).

Hussain, S., \& Oosthuizen, P H. (2012). Numerical investigations of buoyancy-driven natural ventilation in a simple atrium building and its effect on the thermal comfort conditions. Applied Thermal Engineering 40, 358-372.

Lu, Y. (2007). Practical Design Manual for Heating and Air Conditioning (2nd ed). China Architecture \& Building Press. Beijing (China) (in Chinese).

Megri A. C., \& Haghighat F. (2007). Zonal modeling for simulating indoor environment of buildings: review, recent developments, and applications. Hvac \& $R$ Research 13, 887-905.

Norrefeldt, V., Grün, G., Sedlbauer, K. (2012). VEPZO Velocity propagating zonal model for the estimation of the airflow pattern and temperature distribution in a confined space. Building \& Environment 48, 183 194.

Pan, D., Xu, X., Wang, Y., Wang, L., Shao, J. (2018). Numerical simulation on air distribution in large spaces-A literature review. $H V \& A C 48,131-138$ (in Chinese with English abstract).

Patankar, S. V. (1980). Numerical heat transfer and fluid flow. Hemisphere Pub. Corp. Washington (the United States).

Saxon, R. (1986). Atrium buildings development and design (2nd ed). Architectural Press. London (UK).

Yoshiroku, T., Hitoshi, T., Tetuya, A., Takao, T. (1999).

Building Environmental Engineering II. Inoueshoin Co,

Ltd. Tokyo (Japan) (in Japanese). 


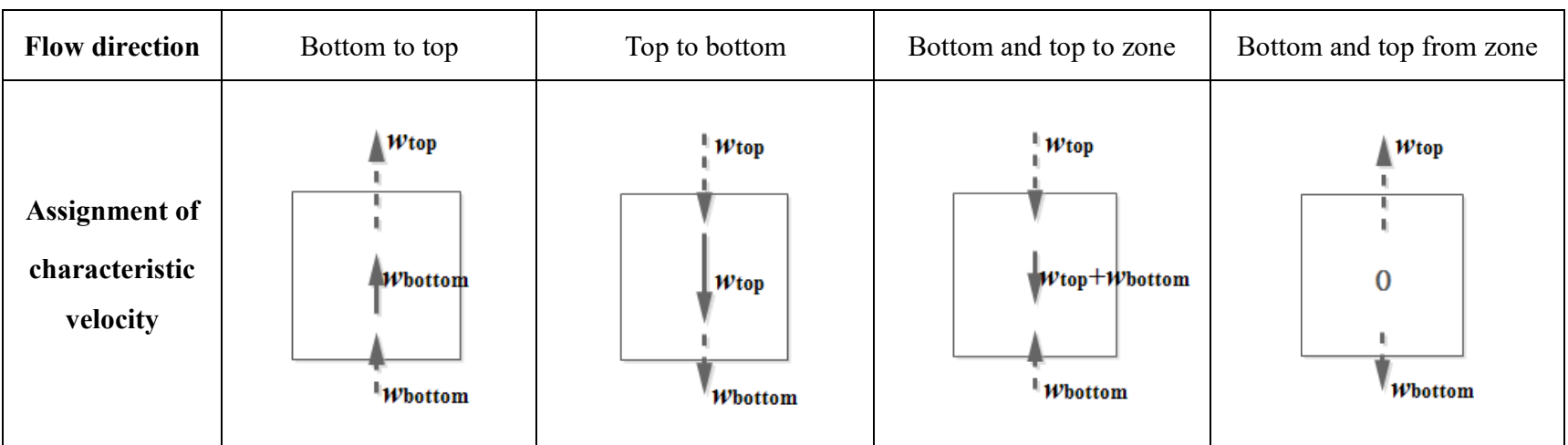

Note: dotted arrow represents airflow across zone boundary; solid arrow stands for characteristic velocity of zone; w denotes velocity vector in z-direction.

Figure 3: Assignment of the characteristic velocity component of a zone in z-direction.

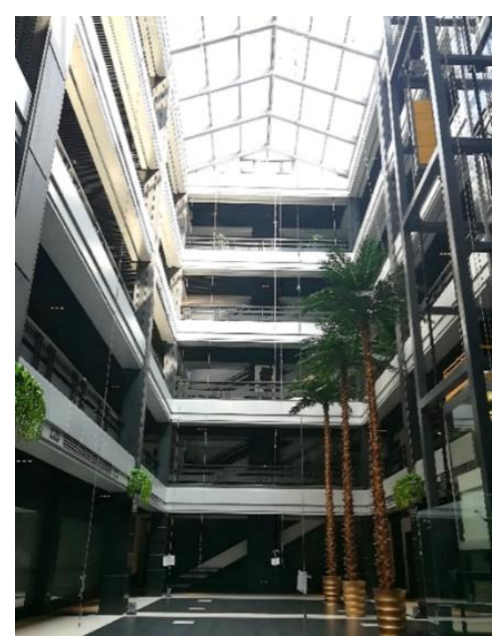

Figure 5: Photo of the atrium for case study.

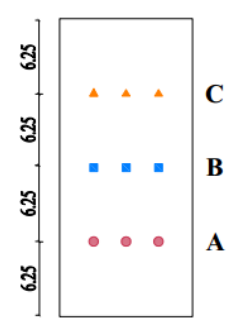

Top view

$2.75,275,2.75,2.75$

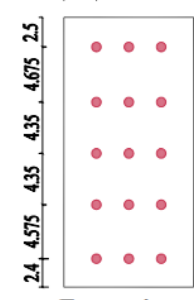
$\mathbf{A} / \mathbf{B} / \mathbf{C}$

A Temp. testing point on plane $\mathrm{C}$

- Temp. testing point on plane B

- Temp. testing point on plane A

- Temp. testing point on floor/internal wall

Unit: m

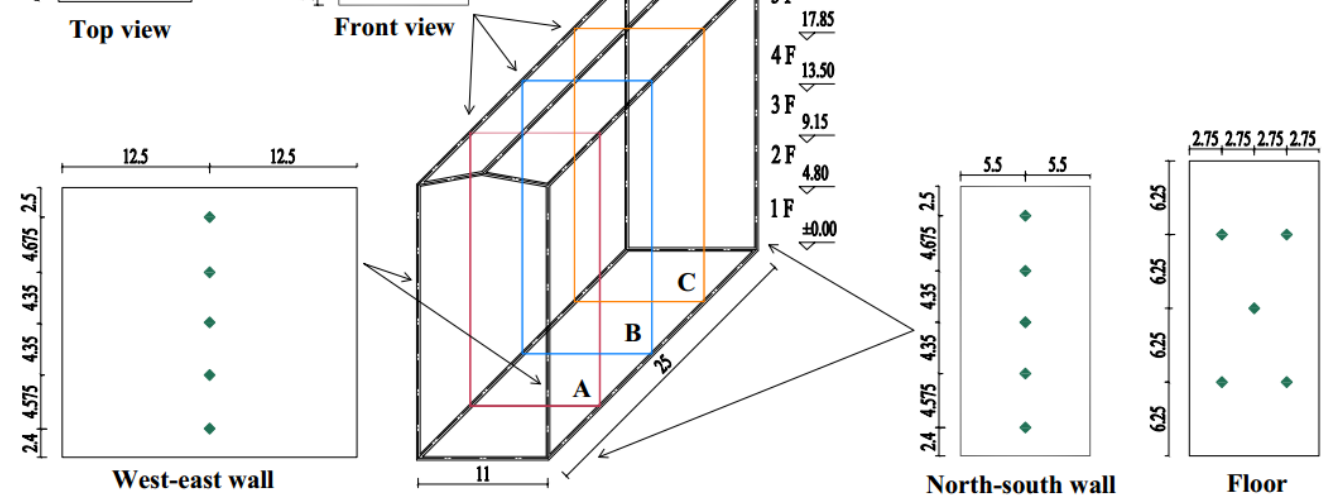

Figure 6: Schematic of temperature testing points inside the atrium space and on the internal faces. 


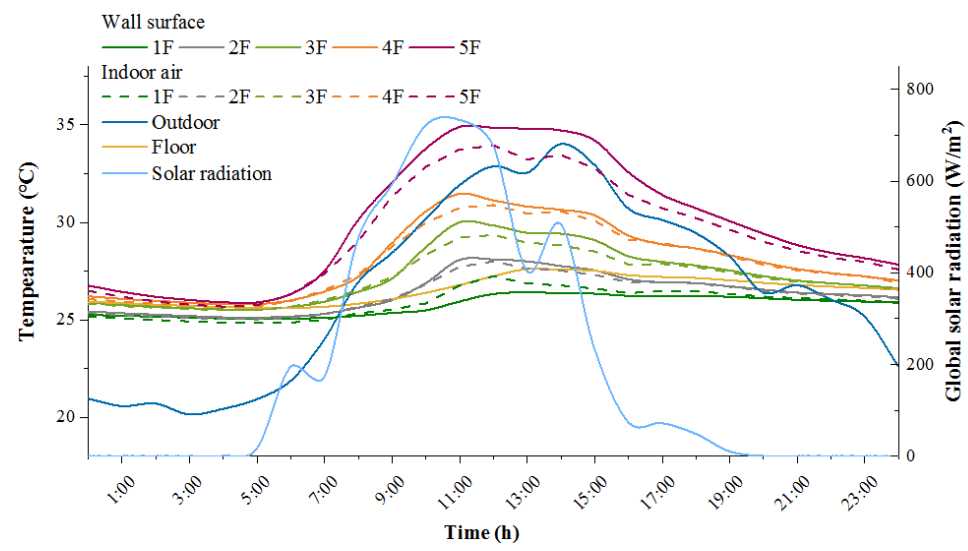

Figure 8: Measurement results over the course of one day.

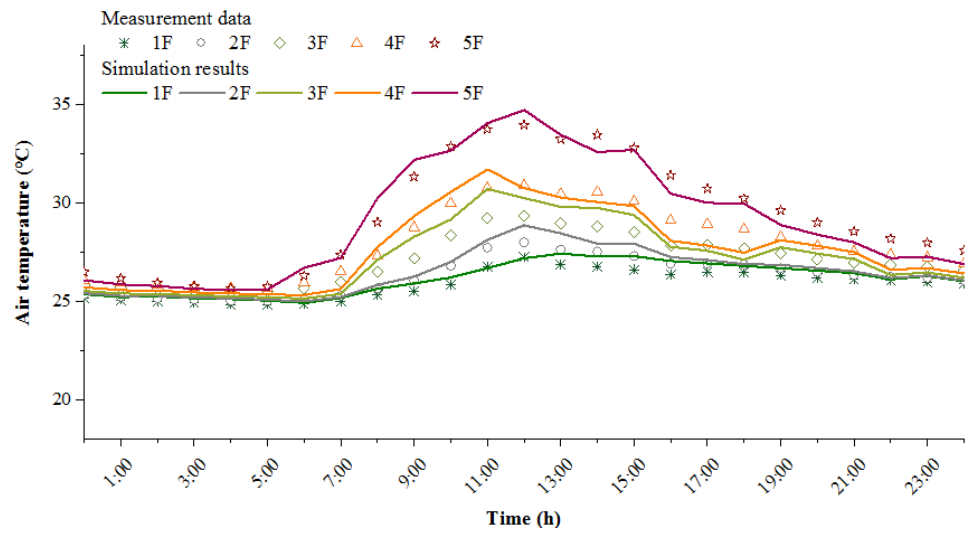

Figure 9: Comparison of simulated and measured temperature distributions over the course of one day.
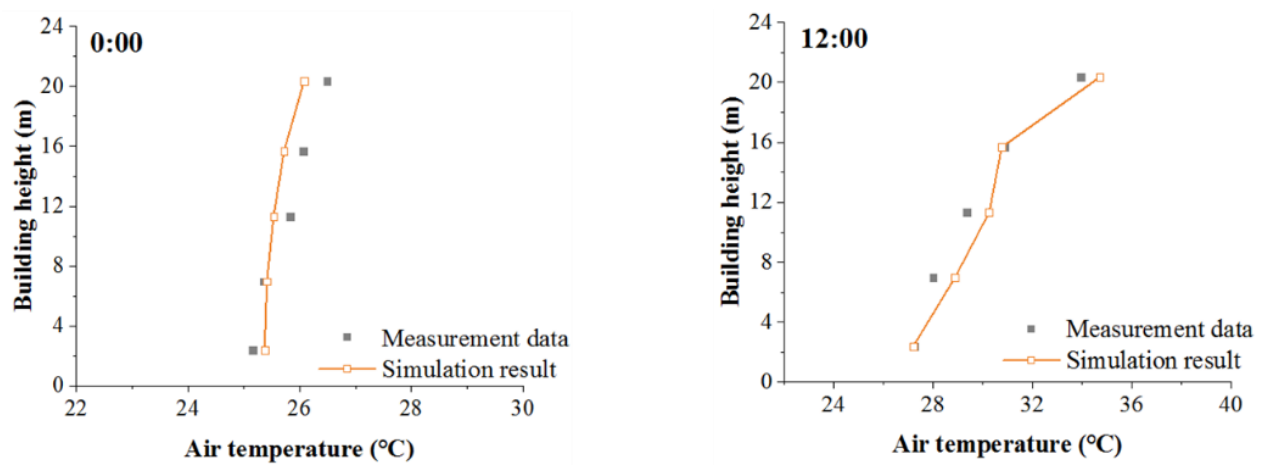

Figure 10: Comparison of simulated and measured air temperatures over the height at typical moments.

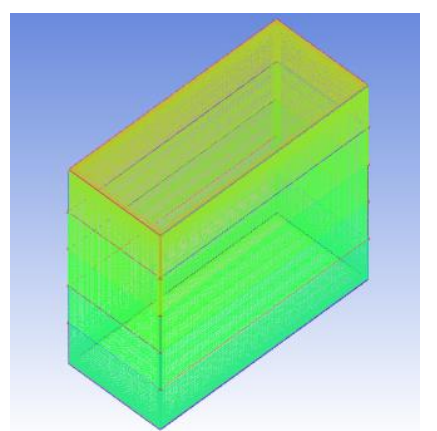

Figure 11: Mesh structure for CFD simulation.

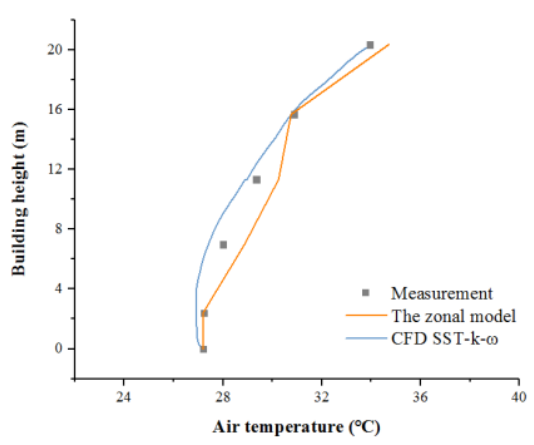

Figure 12: Comparison of air temperature distributions obtained from the measurement, the zonal model and CFD. 